\title{
Behavioral responses of free-ranging blue crabs to episodic hypoxia. I. Movement
}

\author{
Geoffrey W. Bell*, David B. Eggleston, Thomas G. Wolcott \\ North Carolina State University, Department of Marine, Earth, and Atmospheric Sciences, Raleigh, North Carolina 27695-8208, USA
}

\begin{abstract}
Very little is known about how periodic hypoxic intrusions into shallow, nearshore habitats influence local migration patterns of mobile species such as the blue crab Callinectes sapidus. These hypoxic events may cause direct and indirect mortality of crabs as well as alter their distribution and abundance patterns. We used biotelemetry techniques with concurrent hydrographic measurements to monitor movement responses of free-ranging crabs to the spatiotemporal dynamics of hypoxic upwelling events. Shallow areas $(<1.7 \mathrm{~m}$ depth) were rarely hypoxic $(<1 \%$ of the time) and should offer refuge for mobile organisms that avoid low dissolved oxygen (DO) concentrations during hypoxic upwelling events within the Neuse River Estuary (NRE), North Carolina, USA. Free-ranging blue crabs generally attempted to avoid hypoxic water $\left(<4 \mathrm{mg} \mathrm{l}^{-1}\right)$ by moving inshore towards higher DO concentrations; however, crabs were unsuccessful at moving to normoxic water $\left(>4 \mathrm{mg} \mathrm{l}^{-1}\right)$ after exposure to hypoxia during upwelling events. Furthermore, telemetered crabs sometimes remained within severely hypoxic water $\left(<2 \mathrm{mg} \mathrm{l}^{-1}\right)$ for several hours. We discuss potential behavioral mechanisms that may explain these surprising results and compare the movement response of our individuals to the population-level movement responses inferred from trawling studies. To better understand the impacts of episodic hypoxic upwelling events on local blue crab populations, future studies need to identify the mechanisms blue crabs use to detect hypoxia and to orient towards more suitable (i.e. normoxic) habitats. Our results suggest that the movement responses of individuals to disturbance events can be used to predict changes in the distribution and abundance patterns of local populations.
\end{abstract}

KEY WORDS: Avoidance behavior $\cdot$ Hypoxia $\cdot$ Movement $\cdot$ Biotelemetry $\cdot$ Blue crab $\cdot$ Callinectes sapidus · Orientation · Upwelling $\cdot$ Neuse River Estuary $\cdot$ Estuary

\section{INTRODUCTION}

Hypoxia (low dissolved oxygen; $<2 \mathrm{mg} \mathrm{l}^{-1}$ ) and anoxia (no dissolved oxygen $[\mathrm{DO}]_{i}=0.0 \mathrm{mg} \mathrm{l}^{-1}$ ) are often a consequence of eutrophication and are increasing in frequency, magnitude, and duration in coastal ecosystems throughout the world (Diaz \& Rosenberg 1995). Hypoxia is generally a seasonal phenomenon in temperate estuaries, and is usually restricted to deeper water basins, which remain hypoxic for most of the summer. Hypoxic 'dead zones' often form in deep channels (Officer et al. 1984); thus, reducing the amount of usable habitat for mobile organisms and concentrating them in shallower zones where oxygen concentrations are relatively high (Pihl et al. 1991,
Breitburg 1992, Lenihan et al. 2001). The spatial and temporal extent of hypoxic water can be dynamic because winds and tides periodically cause hypoxic bottom water to upwell onto shallow, nearshore habitats (Sanford et al. 1990, Breitburg 1992, Luettich et al. 2000). The direct and indirect effects of these episodic hypoxic upwelling events on mobile species are poorly understood.

Hypoxic events can modify distribution and abundance patterns of large mobile fish and some crustaceans, including blue crabs (Callinectes sapidus). In general, mobile organisms avoid hypoxic or anoxic water in deep areas by moving to shallow refuge habitats where DO concentrations are higher, and subsequently reinvade previously hypoxic deeper water 
after DO concentrations improve (Pihl et al. 1991, Breitburg 1992, Lenihan et al. 2001). For example, during periodic hypoxic intrusions into nearshore habitats (i.e. hypoxic upwelling events), adult blue crabs are hypothesized to migrate from deeper water where DO concentrations are lowest towards shallower water where DO concentrations are higher (Pihl et al. 1991). When hypoxic water recedes from shallower nearshore areas (i.e. relaxation events), blue crabs presumably emigrate back towards deeper water where they may take advantage of infaunal prey that are slow to recover from hypoxic stress (Pihl et al. 1991). The migratory response of mobile fish and crustaceans to hypoxia concentrates large numbers of these organisms within shallow refuge habitats, thereby causing crowding (Loesch 1960) that may intensify biological interactions (Lenihan et al. 2001).

Inferences concerning the effects of hypoxia on movement patterns of mobile species have come from

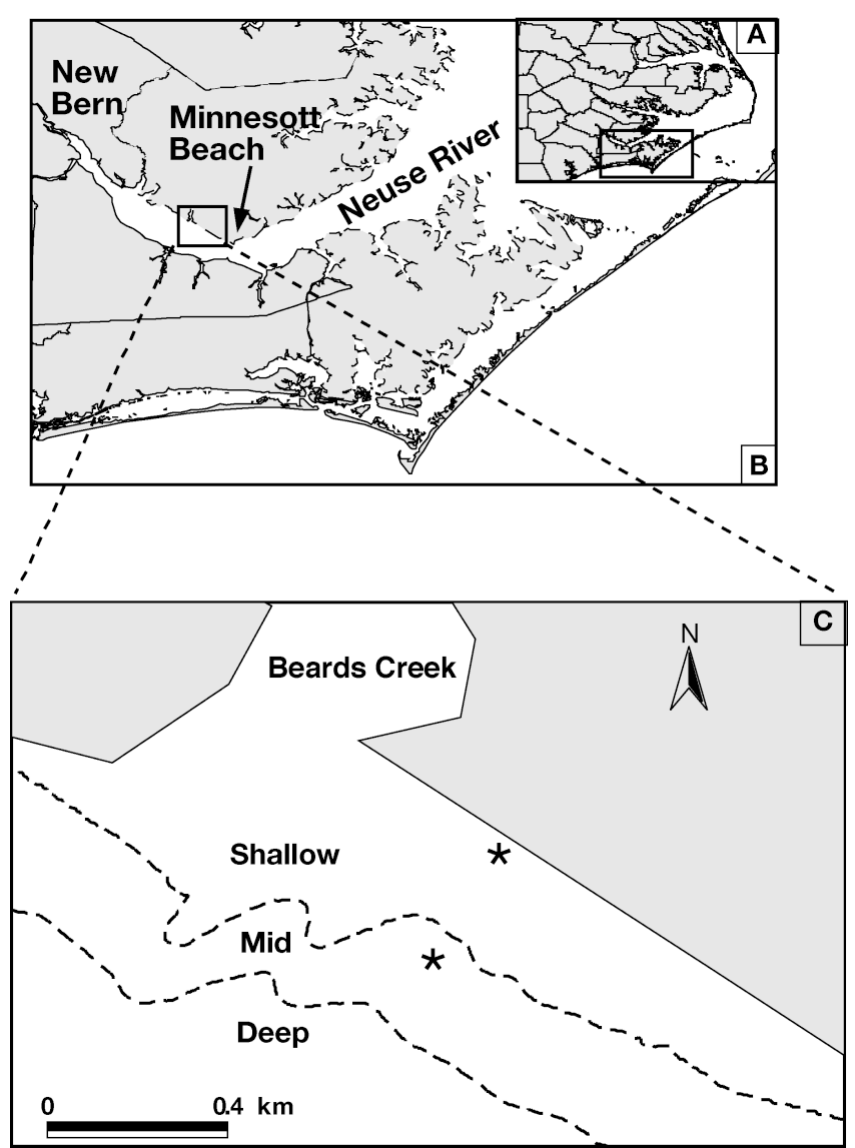

Fig. 1. Study site in the Neuse River, NC, USA. Panel A is the coastal region of North Carolina. Panel B is the Neuse River Basin. Panel $\mathrm{C}$ is the study site showing 3 depth strata (shallow: depth range $=0.9$ to $1.7 \mathrm{~m}$; mid-depth: 1.7 to $3.7 \mathrm{~m}$ ); deep: 3.0 to $4.6 \mathrm{~m}$ ). Asterisks denote the locations of the 2 in situ hydrographic instruments repeated sampling of estuarine habitats using fish traps and trawls (Pihl et al. 1991, Breitburg 1992, Lenihan \& Peterson 1998, Lenihan et al. 2001). Although these studies have identified large-scale changes in distribution and abundance patterns of mobile species in relation to hypoxia, there is little, if any, information on fine-scale behavioral responses of mobile species to dynamic hypoxia. Accurate information on fine-scale movement responses of free-ranging animals is essential for evaluating hypotheses generated from studies that infer behavioral responses from distribution and abundance patterns.

In this study, we used biotelemetry with concurrent hydrographic measurements to track the movements of free-ranging blue crabs in response to episodic hypoxia within the Neuse River Estuary (NRE), North Carolina, USA. The specific objectives of this study were: (1) to describe fine spatial $(<1 \mathrm{~km})$ and temporal (hourly) scale dynamics of periodic hypoxic upwelling events; (2) to identify movement responses of individual, free-ranging blue crabs to dynamic hypoxia; and (3) to describe diel patterns of crab movement behavior. Our study tested 2 general hypotheses concerning blue crab movements in response to episodic hypoxia: (1) free-ranging crabs would avoid hypoxia and move inshore towards higher DO and normoxic water when DO dropped to hypoxia (i.e. upwelling); and (2) freeranging crabs would move offshore towards lower DO and normoxic water when DO increased from hypoxic concentrations (i.e. relaxation).

\section{MATERIALS AND METHODS}

Study site. The study was conducted along the northern shore of the NRE, just upriver of Minnesott Beach, and near the mouth of Beards Creek (Fig. 1). The NRE is a shallow, mesohaline estuary that experiences seasonal bottom water hypoxia during summer months. Hypoxic bottom water develops most frequently in the deeper upstream portions of the NRE, and commonly covers 20 to $40 \%$ of the bottom (Eby 2001). Hypoxic water can cover $100 \mathrm{~km}^{2}$ of the bottom in the NRE and is thought to be an important cause of the near complete mortality of infaunal clams (Macoma sp.) in some areas (Buzzelli et al. 2002). Clams are an important benthic prey for many demersal fish and crustaceans (Hines et al. 1990). Poor water quality, in combination with a reduction in food in hypoxic and anoxic zones has presumably restricted fish and crabs to shallower nearshore habitats (Eby 2001, McClellan 2001, Eby \& Crowder 2002). Water circulation patterns in the NRE are controlled primarily by winds. Changes in wind direction often produce relatively rapid upwelling of hypoxic bottom water during the summer 
months (Luettich et al. 2000). Winds from the southwest cause hypoxic upwelling along the southern shore, whereas northeast winds cause hypoxic upwelling on the northern shore at our study site. Upwelled hypoxic water may remain in shallow habitats from hours to days, depending on wind patterns, until it recedes back to the deep basins of the river (relaxation of hypoxia). Thus, the NRE is ideal for measuring the behavioral response of mobile animals, such as blue crabs, to episodic hypoxic events.

The study site was divided into 3 depth strata (Fig. 1) based on the occurrence of hypoxia within each stratum. The deep stratum (depth range $=3.0$ to $4.6 \mathrm{~m}$; $\bar{x}=3.7 \mathrm{~m}$ ) was always hypoxic if hypoxia was present within the study site. The mid-depth stratum (depth range $=1.7$ to $3.0 \mathrm{~m} ; \bar{x}=2.2 \mathrm{~m}$ ) only experienced hypoxia during upwelling events, and the shallow stratum (depth range $=0.9$ to $1.7 \mathrm{~m} ; \bar{x}=1.3 \mathrm{~m}$ ) was rarely hypoxic. The study area was roughly $2.15 \mathrm{~km}^{2}$ and had a mean depth of $2.4 \mathrm{~m}$. Summer salinity ranged from 10 to17 psu.

Fixed station hydrographic measurements. To qualitatively describe spatial and temporal variability in hypoxic upwelling events within our study site, discrete DO, temperature, and salinity were measured simultaneously at 2 fixed locations (shallow and mid-depth; see Fig. 1) with YSI model 6920 instruments. Hypoxic upwelling events in the NRE are characterized by the occurrence of high salinity and low DO bottom water in nearshore habitats (Luettich et al. 2000). For this portion of the study, we defined hypoxia as DO concentrations less than $2 \mathrm{mg} \mathrm{l}^{-1}$ (Luettich et al. 2000). The instruments were deployed 8 times from late July through September 2001 for 3 to $5 \mathrm{~d}$. The mid-depth location was a US Coast Guard channel marker (depth range = 1.9 to $2.4 \mathrm{~m}$ ) and the shallow station was a private resident's dock (depth range $=0.5$ to $1.1 \mathrm{~m}$ ). Each instrument was fastened vertically with stainless steel hose clamps to pilings, such that the probes were approximately $10 \mathrm{~cm}$ off the sediment surface. The instruments were programmed to record water temperature, salin-

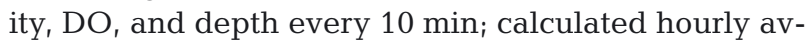
erages are reported below. After each deployment, the instruments were retrieved, cleaned thoroughly, and calibrated before redeployment.

Telemetry design and tracking. We used a multichannel biotelemetry system to monitor movement of individual free-ranging blue crabs. The biotelemetry system was adapted from previous designs used to observe behavior of free-ranging blue crabs (Wolcott \& Hines 1989, Clark et al. 1999a,b, 2000). The electronic circuitry of the transmitter was packaged in shrink tubing which was molded to conform to the dorsal surface of the carapace (to reduce drag), and filled with mineral oil to couple sound between the transducer and water. The packaged transmitter was bonded to the dorsal surface of the carapace using cyanoacrylate glue and fastened with metal wire to the lateral spines (see Fig. 2 in Clark et al. 1999a). Transmitters were also equipped with external wires and electrodes that were fastened to the carapace to monitor feeding and agonistic behaviors. The results from the feeding portion of our study will be reported in a subsequent manuscript. Transmitters were approximately $80 \mathrm{~mm}$ long, $25 \mathrm{~mm}$ wide, and weighed about $24 \mathrm{~g}$ in air. Each crab was held for 12 to $24 \mathrm{~h}$ prior to release to ensure that the transmitter was functioning properly and that the crab was not injured during the tagging process (approximately $1 \mathrm{~h}$ of preparation time). Previous biotelemetry studies indicate that transmitters of similar design do not interfere with common blue crab behaviors such as movement, feeding, agonism, and mating (Nye 1989, Wolcott \& Hines 1989, 1990, Clark et al. 1999a, 2000).

Fourteen adult, intermolt crabs (carapace width [CW] range $=135$ to $175 \mathrm{~mm}$ ) were collected from the study site using crab pots. Only males were used in this study because females of similar size migrate downriver during this period to spawn and hatch larvae (Judy \& Dudley 1970). Tracking occurred from July through September of 2000 and 2001. Mark recapture data from this area suggest that adult blue crab migration patterns are primarily downriver (E. G. Johnson, pers. comm.); therefore, telemetered crabs were released at upriver locations within the study site (near the mouth of Beards Creek) to reduce the risk of crabs leaving the study site during tracking periods. Crabs were released during the day and night at locations that varied in DO concentration $\left(3\right.$ to $\left.8 \mathrm{mg} \mathrm{l}^{-1}\right)$ and depth (1 to $4 \mathrm{~m}$ ). Crabs were tracked continuously for 72 to $96 \mathrm{~h}$ with occasional interruptions due to severe weather or boat problems. Tracking was terminated early $(<42 \mathrm{~h})$ for 4 crabs because either the transmitter failed, the crab died, the crab was mating (consequently rarely moving or feeding), or the crab had not moved or fed in over $12 \mathrm{~h}$.

We tracked the movement of individual crabs aboard a $6 \mathrm{~m}$ boat using a Sonotronics USR-5W ultrasonic receiver and unidirectional hydrophone. Crabs were relocated every 40 to $60 \mathrm{~min}$, or earlier if it appeared that they would move out of listening range. The accuracy of pinpointing the true location of a crab varied depending on the amount of interference from wind and boat propellers; however, a pilot study suggested that we were always accurate to within $3 \mathrm{~m}$. A crab's position was recorded by marking the boat's location using a differential global positioning system (DGPS). DGPS precision is also within $3 \mathrm{~m}$ (Collazo \& Epperly 1995), thus, there was some small error in recording the true position of crabs due to inaccuracy of tracking equipment and imprecision from DGPS. 
Hydrographic measurements during tracking and DO scenarios. As soon as a crab was relocated, we measured 'initial' surface and bottom water temperature, DO, and salinity with a YSI Model 85 handheld instrument, depth (to the nearest $0.3 \mathrm{~m}$ ) with the boat's depth finder, and recorded the date and time using the boat's DGPS. Additionally, 'final' bottom hydrographic measurements were recorded prior to moving to the next relocation point, so that changes in DO at each location could be calculated by subtracting 'final' from 'initial' measurements.

Changes in DO at each relocation point were assigned to 1 of 6 DO scenarios. Three of the scenarios were assumed to represent DO changes that blue crabs would encounter during hypoxic upwelling events. DO could decrease from: (1) normoxia ( $>4 \mathrm{mg} \mathrm{l}^{-1}$ ) to mild hypoxia ( 2 to $\left.4 \mathrm{mg} \mathrm{l}^{-1}\right)_{i}(2)$ normoxia to severe hypoxia $\left(<2 \mathrm{mg} \mathrm{l}^{-1}\right)_{i}$ or (3) mild hypoxia to severe hypoxia. The remaining 3 DO scenarios were assumed to approximate changes in DO during the relaxation of hypoxic events. DO could increase from: (1) severe hypoxia to mild hypoxia; (2) severe hypoxia to normoxia; or (3) mild hypoxia to normoxia. We used 2 designations for hypoxia (mild and severe) for the analyses of behavior. We chose $4 \mathrm{mg} \mathrm{l}^{-1}$ as the cut-off between normoxia and mild hypoxia because laboratory results suggest that blue crabs begin to alter their behavior and physiology below this DO concentration (Batterton \& Cameron 1978, Das \& Stickle 1994). We chose $2 \mathrm{mg} \mathrm{l}^{-1}$ as the cut-off between mild and severe hypoxia because below this DO concentration anaerobic respiration is activated and survival is low (Das \& Stickle 1993, Mangum 1997).

Statistical analyses. To assess blue crab movement responses to hypoxic upwelling and relaxation events, we measured 3 movement characteristics of telemetered crabs (directional movement, movement to higher or lower DO concentrations, and movement to normoxic water) for the 6 DO scenarios. We hypothesized that during hypoxic upwelling events, telemetered crabs would: (1) exhibit directed movement towards the NE shoreline of the NRE (approximately towards a 0 to $90^{\circ}$ compass heading; Fig. 1); (2) move to higher DO concentrations than the previous location (i.e. avoid hypoxic water); and (3) move to normoxic water at the subsequent relocation point. The latter movement response was used to assess how successful crabs were at avoiding hypoxic water. Conversely, we hypothesized that during relaxation events crabs would: (1) display directed movement away from the NE shoreline of the NRE (approximately towards a 180 to $270^{\circ}$ compass heading; Fig. 1 ); (2) move to lower DO concentrations than at the previous location; and (3) move to normoxic water at the following location where they could feed on infaunal prey that had reduced their burial depth in response to hypoxia.
Directional movement: To quantify directional movement, we first calculated the heading crabs took (in compass degrees) between consecutive relocation points and assigned each heading to the appropriate DO scenario. We used circular statistics to calculate a single mean heading for each crab during all 6 DO scenarios. We used these mean headings as replicates for 6 separate Rayleigh's tests (one for each DO scenario). Rayleigh's tests calculate the amount of dispersion around mean headings (assessed with the length of the mean vector ' $r$ ', which ranges from 0 to 1 and is inversely related to dispersion) and determine whether an observed circular distribution of headings is significantly different from a uniform distribution (Zar 1984). For instance, if the distribution of observed crab headings was significantly different than a uniform distribution when DO dropped from normoxia to severe hypoxia, we could conclude that crabs demonstrated directed movement during this scenario.

Avoidance behavior: To determine whether crabs avoided and were successful at evading hypoxia, we first calculated the percentage of times each crab moved to higher DO and to normoxic water for the 3 scenarios where DO decreased to hypoxia. We used separate 1 sample $t$-tests to test the overall null hypothesis that the proportion of times crabs moved to higher DO and normoxic water was greater than (1-sided test) an assumed random response (50\%). For example, although we expected crabs to move to normoxic water during upwelling events, we tested the null response that the proportion of times that crabs moved to normoxic water was greater than $50 \%$ for all 3 upwelling scenarios. The same calculations and tests were applied to scenarios where DO increased from hypoxia, except we hypothesized that crabs would move to lower DO and normoxic water greater than $50 \%$ of the time during relaxation events.

Reducing the numerous movement observations along each crab's telemetry track to a single replicate in each of the statistical tests made each replicate independent and removed the possibility of spatial and temporal autocorrelation. Many crabs did not experience all 6 DO scenarios; therefore, sample sizes varied from 5 to 8 among tests. Only 1 crab experienced an increase in DO from severe hypoxia to normoxia $(\mathrm{n}=1)$. Thus, results for this scenario are not reported.

Diel movement patterns: To determine whether free-ranging crabs displayed diel patterns in speed of movement, relocation points were classified according to time of day: (1) day ( $1 \mathrm{~h}$ after sunrise to $1 \mathrm{~h}$ before sunset); (2) night (1 $\mathrm{h}$ after sunset to $1 \mathrm{~h}$ before sunrise); and (3) twilight ( $1 \mathrm{~h}$ before and after sunrise and sunset). Speed was expressed in $\mathrm{m} \mathrm{h}^{-1}$ and computed using distances between successive relocations (estimated using ArcView 3.1 software) divided by the cor- 
responding time between relocations. For each of the 3 diel periods, we calculated the mean speed for each crab. We also calculated an overall mean speed (irrespective of diel period) for each crab and used a paired-sample $t$-test to determine whether speed differed significantly between diel period means and the overall mean $(\mathrm{n}=14)$.

In all statistical tests, the assumption of normality was tested with a Kolmogorov-Smirnov (K-S) test. In instances where data were not normal for paired sample $t$-tests, a nonparametric Wilcoxon rank test was used. For 1 sample $t$-tests, when transformations were not successful at achieving normality, we used the raw data because normal probability plots did not suggest severe skewness in most cases, and $t$-tests are robust to deviations from normality (Zar 1984).

\section{RESULTS}

\section{Fixed station hydrography}

During July to September 2001 at the mid-depth station (depth range $=1.9$ to $2.4 \mathrm{~m}$ ), we recorded a total of 32 hypoxic events throughout the $35 \mathrm{~d}$ monitoring period. These hypoxic events were variable in terms of mean DO concentration $\left(\bar{x}=1.16 \pm 0.10 \mathrm{mg} \mathrm{l}^{-1}\right.$; DO range $=0.27$ to $1.94 \mathrm{mg} \mathrm{l}^{-1}$ ) and duration $\bar{x}=5.3 \pm$ $1.14 \mathrm{~h}$; range $=1$ to $28 \mathrm{~h}$ ). The onset of hypoxic upwelling events was characterized by a rapid drop in DO (as fast as $5.81 \mathrm{mg} \mathrm{l}^{-1} \mathrm{~h}^{-1}$ ); temperature decreased and salinity increased at slower rates than DO (Fig. 2A). The increase in salinity and decrease in DO and temperature indicates that mid-depth hypoxia is associated with upwelled bottom water from the deep basins of the Neuse R. (Luettich et al. 2000). Relaxation of these hypoxic events resulted in a relatively slow rate of change $\left(\bar{x}=0.61 \mathrm{mg} \mathrm{l}^{-1} \mathrm{~h}^{-1}\right)$ back to pre-event levels of DO, temperature and salinity (Fig. 2A). Hypoxia was detected at the shallow station (depth range $=0.5$ to $1.1 \mathrm{~m}$ ) on only 2 of the 32 mid-depth hypoxic events (one such event is shown in Fig. 2B). During these 2 events, the shallow station remained hypoxic for 3 (Fig. 2B) and $5 \mathrm{~h}$, whereas the mid-depth station remained hypoxic for 11 and $28 \mathrm{~h}$, respectively. The proportion of total hourly observations that were hypoxic for the mid-depth and shallow stations were 23 and $1 \%$, respectively. Thus, hypoxic events were variable in space and time, particularly at mid-depths, and hypoxic bottom water rarely intruded into the shallowest nearshore habitats, thereby providing refuge for crabs that avoided hypoxia.

The percentage of hourly, mid-depth station observations within a month that were hypoxic increased from July to September $(4.52,25.48$, and $29.30 \%$, respectively). The mean duration of hypoxic events also increased throughout the field season; hypoxic events lasted longer and were more variable in September than other months (Jul: $4.0 \mathrm{~h}$ [SE $\pm 1.0 \mathrm{~h}$ ); Aug: $4.47 \mathrm{~h}[\mathrm{SE} \pm 0.77 \mathrm{~h}]_{i}$ Sep: $\left.6.93 \mathrm{~h}[\mathrm{SE} \pm 2.41 \mathrm{~h}]\right)$. The mean DO concentration per hypoxic event was lowest during August $\left(\bar{x}=0.80 \pm 0.10 \mathrm{mg} \mathrm{l}^{-1}\right)$ and higher in July $\left(\bar{x}=1.58 \pm 0.13 \mathrm{mg} \mathrm{l}^{-1}\right)$ and September $(\bar{x}=1.37 \pm$ $\left.0.16 \mathrm{mg} \mathrm{l}^{-1}\right)$.

\section{Fine-scale movements of free-ranging crabs}

\section{General and diel movement patterns}

Telemetered crabs exhibited 2 general types of movement patterns: (1) slow meandering within relatively small areas; and (2) relatively fast directional movements that covered large distances (Fig. 3).
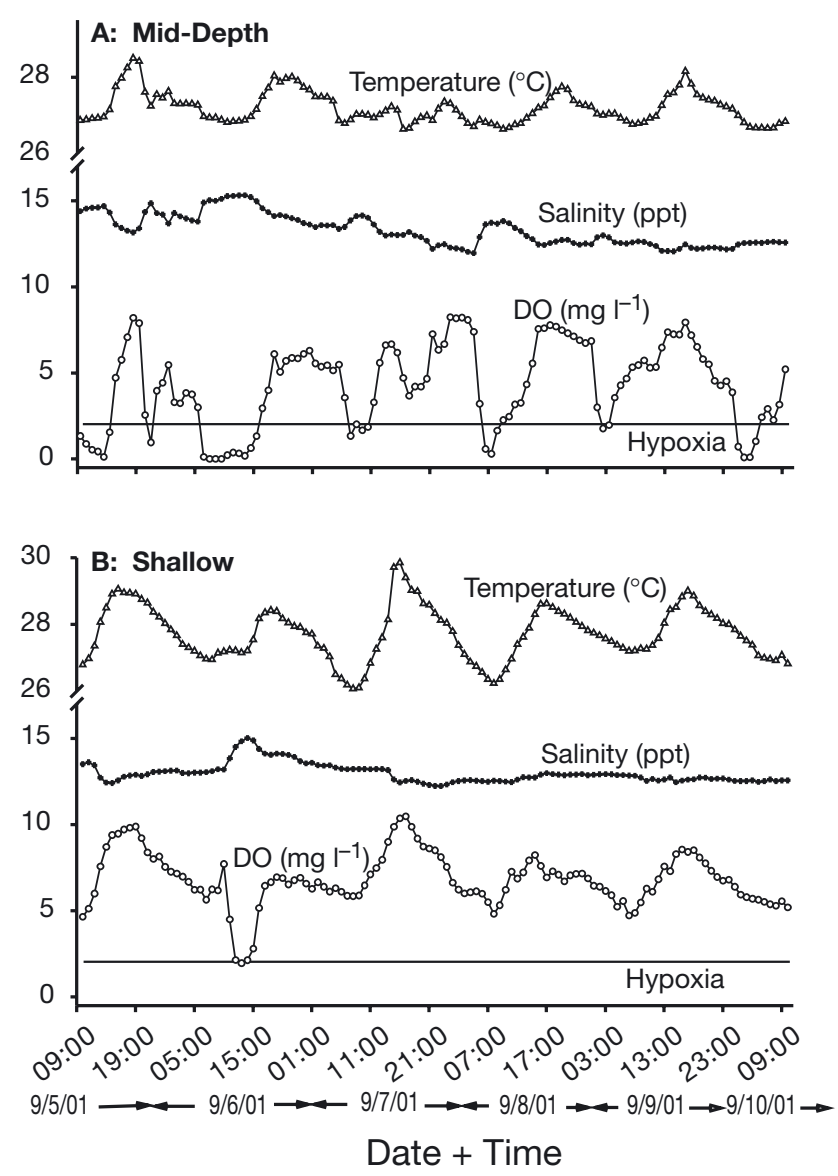

Fig. 2. Time series of hourly DO, temperature and salinity measurements from (A) the mid-depth sonde (1.9 to $2.4 \mathrm{~m}$ deep) and (B) shallow sonde (0.5 to $1.1 \mathrm{~m}$ deep) from September 5 to 10,2001 . Horizontal solid line represents the threshold DO for hypoxia $\left(2 \mathrm{mg} \mathrm{l}^{-1}\right)$ 

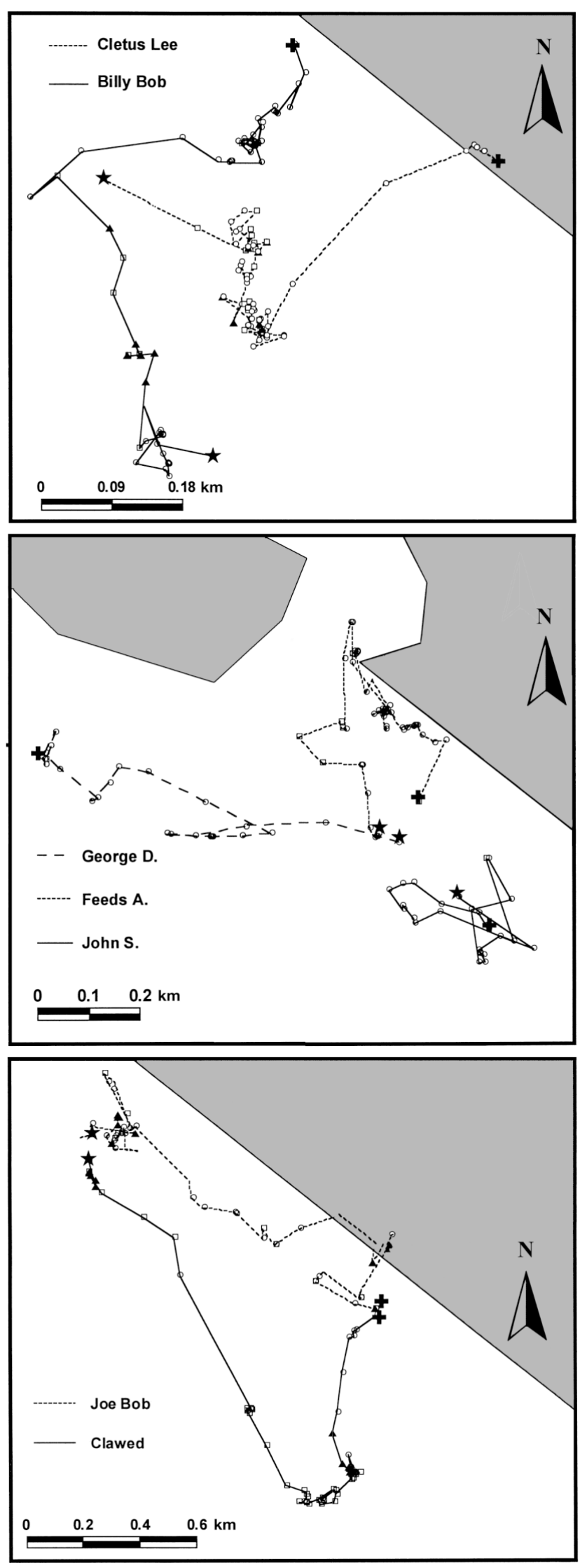

Meandering lasted for hours to days, whereas rapid movements lasted only a few hours. Individual crabs were highly variable with respect to mean speed $(\bar{x}=$ $49.1 \pm 6.7 \mathrm{~m} \mathrm{~h}^{-1}$; range $=13.91$ to $93.24 \mathrm{~m} \mathrm{~h}^{-1}$ ) and maximum distance traveled in $1 \mathrm{~h}(48.1$ to $606.8 \mathrm{~m})$ (Table 1). Although crabs were relocated across all depths within the study site, they occurred more frequently in shallow $(<1.7 \mathrm{~m})$ than mid-depth $(1.7$ to $3.0 \mathrm{~m})$ or deep locations ( 3.0 to $4.6 \mathrm{~m})(58,24$, and $18 \%$ of relocations, respectively). During all fourteen $4 \mathrm{~d}$ tracking periods, crabs never moved to the other side of the river (southwest), but they did tend to move downstream (Fig. 3).

Telemetered crabs exhibited slightly greater speeds during the day $\left(\bar{x}=57.3 \pm 7.4 \mathrm{~m} \mathrm{~h}^{-1}\right)$ than during twilight $\left(\bar{x}=40.69 \pm 7.06 \mathrm{~m} \mathrm{~h}^{-1}\right)$ or night hours $\left(42.23 \pm 9.47 \mathrm{~m} \mathrm{~h}^{-1}\right)$. Speed was significantly different than overall mean speed only during daylight hours (paired sample $t$-test: $t=-2.47, \mathrm{df}=13$, $\mathrm{p}=0.03$ ) (Fig. 4). Thus, blue crabs were more active during daylight hours.

\section{Movement responses to hypoxia}

Although crab encounters with mild ( 2 to $4 \mathrm{mg} \mathrm{l}^{-1}$ ) and severe hypoxia $\left(<2 \mathrm{mg} \mathrm{l}^{-1}\right)$ were generally rare along the nearshore zone of the NRE (Fig. 3), some crabs spent a substantial amount of time within hypoxic water. For example, the percent of crab relocations at sites classified as mildly hypoxic ranged from 0 to $64.5 \%$ among crabs and averaged $15.6 \%$ across all crabs. Similarly, the percent of crab relocations at severely hypoxic sites ranged from 0 to $17.3 \%$ and averaged $6.6 \%$. Crabs were exposed to hypoxia $\left(<4 \mathrm{mg} \mathrm{l}^{-1}\right)$ for up to 32 consecutive hours, whereas continuous exposure to severe hypoxia $\left(<2 \mathrm{mg} \mathrm{l}^{-1}\right)$ lasted up to $6 \mathrm{~h}$.

Crab encounters with hypoxia occurred at all depth strata but were most common at either mid- or deep depths. For example, the percent of relocations that were severely hypoxic for shallow (depths $<1.7 \mathrm{~m}$ ), mid-depth (1.7 to $3.0 \mathrm{~m}$ ) and deep (3.0 to $4.6 \mathrm{~m} \mathrm{deep)}$

Fig. 3. Study site including telemetry tracks for 7 crabs. Each point is a single tracking location along a crab's track that is classified based on whether DO measurements were normoxic $(-)$, mildly hypoxic $(\square)$, or severely hypoxic $(\neg)$. Stars indicate release location, and plus signs show last relocation point for each crab. The time between successive relocations was 40 to $60 \mathrm{~min}$. Dashed lines denote depth contour lines that separate the shallow from mid-depth stratum $(1.5 \mathrm{~m}$ depth), and mid-depth from deep stratum (3.0 m depth) (see Fig. 1). Relocation points on land are due to the coarse spatial resolution of the digital map used in ArcView 
Table 1. Tracking information for individual crabs including release date, carapace width (CW), and duration of tracking events. Also reported are data on general movement patterns for each crab including mean speed $\left(\mathrm{m} \mathrm{h}^{-1}\right)( \pm \mathrm{SE})$ and range. Average speed across crabs is also provided. Exact carapace width measurements for 'Dale Earnhardt' and 'George Dickel' were not available, but were approximately the same size as other crabs. Dates given as mo/d/yr

\begin{tabular}{|lccccc|}
\hline $\begin{array}{l}\text { Release } \\
\text { date }\end{array}$ & Crab ID & $\begin{array}{c}\mathrm{CW} \\
(\mathrm{mm})\end{array}$ & $\begin{array}{c}\text { Tracking } \\
\text { duration } \\
(\mathrm{h}: \mathrm{min})\end{array}$ & $\begin{array}{c}\text { Mean speed } \\
\left(\mathrm{m} \mathrm{h}^{-1}\right) \pm \mathrm{SE}\end{array}$ & $\begin{array}{c}\text { Range } \\
\text { of speed } \\
\left(\mathrm{m} \mathrm{h}^{-1}\right)\end{array}$ \\
\hline $7 / 24 / 00$ & Billy Bob & 154 & $69: 11$ & $47.2 \pm 6.4$ & $0-202.4$ \\
$7 / 31 / 00$ & Billy Rae & 149 & $60: 07$ & $13.9 \pm 2.7$ & $0-81.3$ \\
$8 / 7 / 00$ & Joe Bob & 151 & $73: 53$ & $81.2 \pm 12.3$ & $0-334.1$ \\
$8 / 13 / 00$ & Cletus Lee & 138 & $95: 20$ & $22.8 \pm 3.9$ & $0-243.5$ \\
$8 / 24 / 00$ & Clawed & 135 & $85: 41$ & $51.6 \pm 9.2$ & $0-606.8$ \\
$9 / 11 / 00$ & Uncle Jessie & 152 & $95: 55$ & $17.2 \pm 3.8$ & $0-232.2$ \\
$9 / 19 / 00$ & Boss Hog & 140 & $73: 37$ & $46.2 \pm 8.5$ & $0-346.2$ \\
$9 / 24 / 00$ & Jethro & 148 & $71: 37$ & $42.9 \pm 6.7$ & $0-347.8$ \\
$7 / 22 / 01$ & Dale Earnhardt & $\sim 150$ & $67: 22$ & $29.6 \pm 4.4$ & $0-119.4$ \\
$8 / 8 / 01$ & George Dickel & $\sim 150$ & $30: 21$ & $81.9 \pm 17.1$ & $0-271.3$ \\
$8 / 11 / 01$ & John Steinbeck & 162 & $42: 32$ & $57.0 \pm 13.3$ & $0-291.0$ \\
$8 / 17 / 01$ & Crab Pitt & 175 & $29: 09$ & $67.9 \pm 12.7$ & $0-353.7$ \\
$9 / 5 / 01$ & Cooter & 170 & $26: 34$ & $93.2 \pm 18.8$ & $2.65-382.4$ \\
$9 / 8 / 01$ & Feeds Alot & 159 & $38: 12$ & $35.0 \pm 6.1$ & $0-48.1$ \\
Average & & & & $49.1 \pm 6.7$ & \\
\hline
\end{tabular}

moxia to severe hypoxia was $1.29^{\circ}$ $(\mathrm{r}=0.60)$ and $13.6^{\circ}$ when DO dropped from mild hypoxia to severe hypoxia $(\mathrm{r}=0.71)$; both of which were within the hypothesized heading range ( 0 to 90) (Fig. 6A). The directional headings were significantly different from uniform when DO dropped from mild to severe hypoxia (Rayleigh's test: $\mathrm{p}=0.04$ ), but not when DO dropped from normoxia to severe hypoxia ( $p=0.17$ ) or normoxia to mild hypoxia $(\mathrm{p}=0.56)$.

During relaxation events, telemetered crabs did not immediately reinvade lower DO or normoxic habitats, nor did they exhibit directional offshore movement. For example, although the percentage of times crabs moved to lower DO, yet normoxic water was greater than the expected $50 \%$ random response when DO increased from mild hypoxia to normoxia $(64.58 \%+12.77 \%$ and $56.25 \pm$ $15.08 \%$, respectively), the percentages

strata averaged $4.2,13.3$, and $7.0 \%$, respectively across crabs. The percent of relocations at the shallow, mid-depth, and deep strata that were mildly hypoxic were $7.6,5.9$, and $28.4 \%$, respectively. Thus, crabs are more likely to encounter hypoxic bottom water at depths greater than $1.7 \mathrm{~m}$.

During upwelling events telemetered crabs generally attempted to avoid hypoxic water by moving to higher DO, but were not successful at reaching normoxic water. For example, the proportion of times that crabs moved to higher DO was greater than would be expected at random for all 3 decreasing DO scenarios (normoxia to mild hypoxia: $73.81 \pm$ $7.99 \%$; mild hypoxia to severe hypoxia: $58.93 \pm$ $16.44 \%$; normoxia to severe hypoxia $100 \pm 0.0 \%$ ) (Fig. 5). The percentages for the normoxia to mild hypoxia scenario were significantly greater than a $50 \%$ random response (1 sample $t$-test: $\mathrm{df}=7, \mathrm{p}=$ 0.01 ) and no statistics were necessary for the normoxia to strong hypoxia scenario because crabs moved to higher DO $100 \%$ of the time. Conversely, although crabs moved to normoxic water more than $50 \%$ of the time when DO dropped from normoxia to severe hypoxia $(\bar{x}=62.5 \pm 15.67 \%)$ (Fig. 5), the percentage was not significantly greater than random (1 sample $t$-test: df $=7, \mathrm{p}=0.23$ ).

During upwelling events, telemetered crabs displayed movement that was weakly oriented in the direction of the shoreline (about $45^{\circ}$ ). The mean directional heading when DO dropped from nor- were not significantly greater than $50 \%$ (1 sided $t$-test: $\mathrm{df}=7, \mathrm{p}=0.15 ; \mathrm{df}=7, \mathrm{p}=0.35$, respectively). Furthermore, the mean headings for DO scenarios where DO increased (mild hypoxia to normoxia: $153.94^{\circ}, \mathrm{r}=0.36$; strong hypoxia to mild hypoxia: $121.25^{\circ}, \mathrm{r}=0.31$ ) were not within the hypothesized heading range $\left(180\right.$ to $\left.270^{\circ}\right)$ and not significantly different than a uniform distribution $(\mathrm{p}=0.43$ and 0.65 , respectively) (Fig. 6B). Therefore, blue crabs encountering hypoxia prior to relaxation events did not reinvade deeper water habitats.

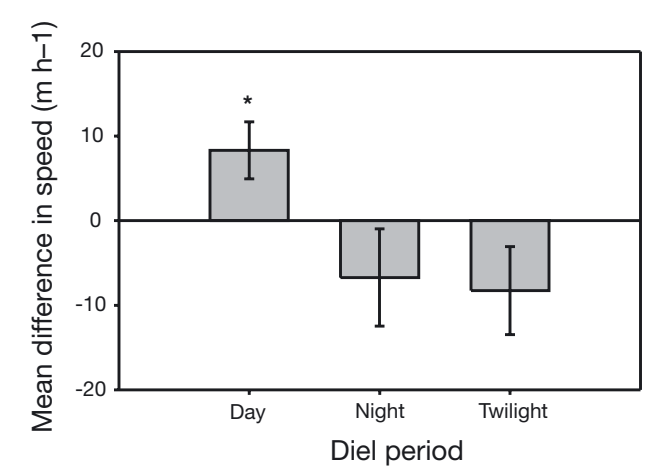

Fig. 4. Diel patterns in telemetered crab speed $\left(\mathrm{m} \mathrm{h}^{-1}\right)$. Plotted is the mean difference in speed $\pm \mathrm{SE}$ between each diel period and the overall mean speed of each crab $(n=14)$. Asterisk denotes significant differences between observed mean and overall mean from paired $t$-tests 

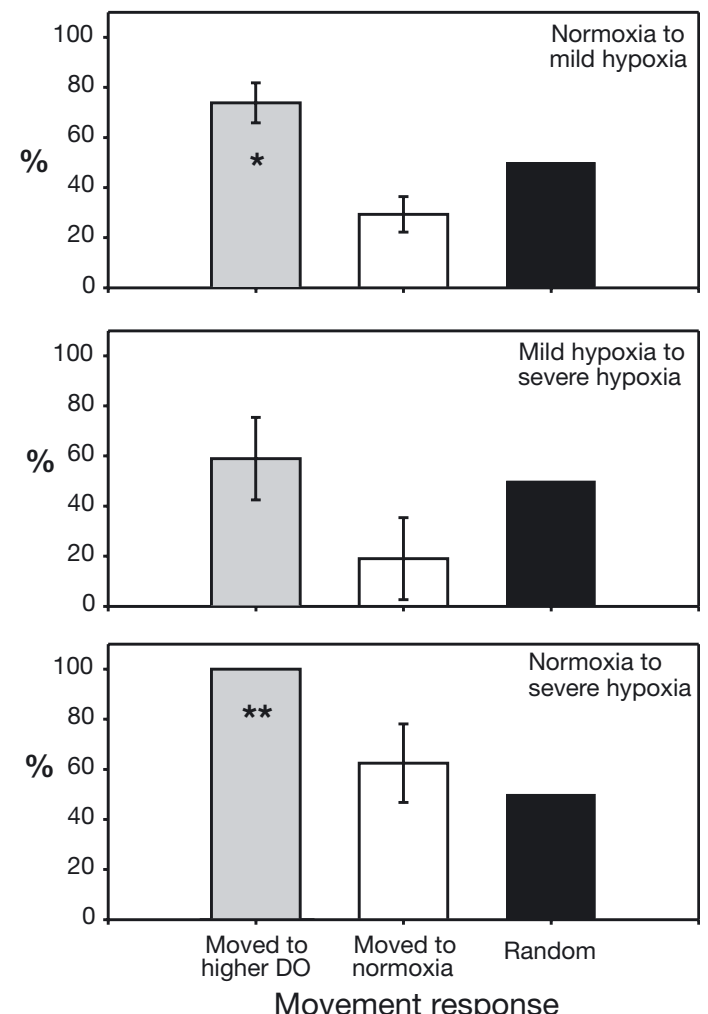

Fig. 5. Movement response of telemetered crabs to 3 DO scenarios representing hypoxic upwelling conditions. The mean percentage of times that crabs moved to higher DO (relative to 'final' DO measurements at previous location) (shaded bars) and normoxic water (open bars) $( \pm \mathrm{SE}$ ) are compared to an expected random response of $50 \%$ (dark bars) for each of the 3 DO scenarios. The single asterisk indicates significant differences $(\alpha<0.05)$ from expected random behavior $(50 \%)$ as tested with 1 sample $t$-tests; the double asterisk indicates that statistics were not necessary because crabs exhibited hypothesized response $100 \%$ of the time

\section{DISCUSSION}

We hypothesized that blue crabs would avoid hypoxic upwelling events by moving inshore to higher DO, normoxic habitats and move offshore during relaxation events. Our results, however, showed that although telemetered blue crabs generally attempted to avoid hypoxia by moving to higher DO concentrations (relative to DO at the previous location), they were largely unsuccessful at escaping hypoxia and remained within hypoxic water for several hours. Furthermore, crabs did not reinvade offshore habitats during relaxation events. Thus, our results were inconsistent with our original hypotheses. Our results, however, may be explained by understanding crustacean oxygen sensory systems, the orientation mechanisms crabs use to respond to chemical stimuli, and the physiological adaptations of blue crabs to hypoxia.
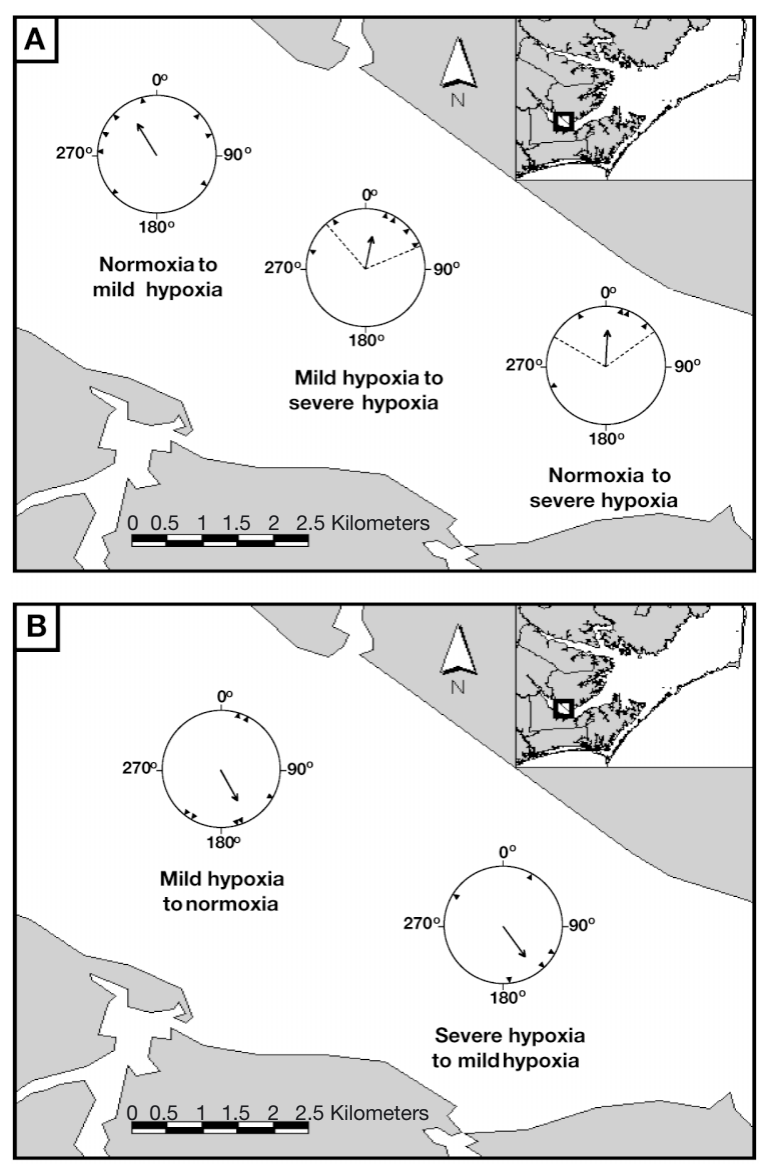

Fig. 6. Circular heading plots for each of (A) the 3 DO scenarios representing hypoxic upwelling conditions and (B) the 2 DO scenarios representing hypoxic relaxation events. Results from the scenario where DO increased from severe hypoxia to normoxia are not reported because of the small sample size $(n=1)$. Small triangles around the inside perimeter of the circles show the mean heading for each crab during the respective DO scenario. Arrow directions indicate the mean heading taken by all crabs for a specific DO scenario and dashed lines represent $95 \%$ confidence intervals about each mean heading. Confidence intervals are not plotted if they spanned a range $>180^{\circ}$

\section{Avoidance behavior mechanisms for hypoxia}

To successfully avoid an unfavorable chemical stimulus an organism must have chemoreceptors to detect the cue and an effective mechanism to orient towards preferred habitats. Blue crabs can detect hypoxia because they alter their behavior (e.g. movement and antennule flick rates) and physiology (e.g. ventilation rates) when exposed to DO concentrations below $4 \mathrm{mg} \mathrm{l}^{-1}$ (Batterton \& Cameron 1978, Das \& Stickle 1994). This suggests that the failure to move to normoxic water may be due to a limitation in the mechanisms used for orienting towards more suitable habi- 
tats. The mechanisms that aquatic animals use to orient away from hypoxia are unknown; however, the ability of blue crabs and other crustaceans to use temporal and spatial chemical gradients in orienting to prey odor plumes (Zhou \& Rebach 1999, Weissburg \& Dusenbery 2002) may also be useful for orientation in areas where hypoxia can be spatially and temporally dynamic.

To detect spatial gradients in chemical concentrations, an animal must have bilaterally paired chemorecptors that are spaced wide enough apart to identify spatial variations in chemical signals (Grasso et al. 2000, Weissburg \& Dusenbery 2002). Animals can then move in the direction of the sensors that are more favorably stimulated (Grasso et al. 2000, Weissburg \& Dusenbery 2002) (i.e. in the direction of sensors detecting stronger concentrations of prey odor or higher DO). Although crustacean oxygen receptors are bilaterally paired, the receptors are located on the gills where they can sense DO only in water that has been drawn into the branchial chambers (inside the carapace) (Taylor 1982). Contact with the body disrupts chemical gradients present near aquatic organisms (Weissburg 1993); therefore, blue crabs may not be able to detect spatial oxygen gradients and may instead rely on temporal oxygen gradients for orientation.

The alternative means of detecting and orienting to DO gradients would be to take temporally separated samples. Collecting multiple measurements of DO at a fixed location over time can be used to determine temporal gradients in DO (i.e. whether DO is increasing or decreasing); however, additional information from another stimulus, such as current direction, is required to decide in which direction to move. Blue crabs and other crustaceans orient up-current when detecting a favorable chemical stimulus (Herrnkind 1983, Weissburg \& Zimmerfaust 1993, Nevitt et al. 1995, Weissburg \& Dusenbery 2002, Weissburg et al. 2003). Conversely, we would expect that when a drop in DO to hypoxic concentrations is detected, blue crabs would orient and move down-current to avoid hypoxia. Successful orientation to currents is dependent on current speed (Weissburg \& Zimmerfaust 1993, Nevitt et al. 1995). If blue crabs use currents to orient away from hypoxia, then movement responses may be affected by the hydrodynamics of upwelling events (e.g. current direction and velocity) which can be variable in the NRE (Luettich et al. 2000).

Differences in blue crab movement patterns among the 3 decreasing DO scenarios tested in this study suggest that hydrodynamics of hypoxic upwelling events may influence movement behavior. For example, increased current velocities can enhance the orientation response to currents for crustaceans (Weissburg \& Zimmerfaust 1993, Nevitt et al. 1995). Telemetered crabs were about 1.5 times more likely to move to higher DO and 3 times more likely to move to normoxic water when DO dropped from normoxia to severe hypoxia than when DO dropped from moderate hypoxia to severe hypoxia or from normoxia to moderate hypoxia. During hypoxic upwelling events in this region of the NRE, the rate of change in DO at a fixed location is positively correlated with upwelling current velocities (R. Luettich, Institute of Marine Sciences, University of North Carolina, pers. comm.). This relationship between the rate of DO change and current speed suggests that severe events (i.e. when DO drops rapidly due to faster upwelling current velocities) may elicit a stronger avoidance response to hypoxic water in blue crabs than do events where DO drops more slowly.

The proposed orientation mechanism (concurrent use of temporal DO gradients and current direction cues) seems adequate for successful avoidance of hypoxia, but our nonsignificant results suggest that crabs were ineffective at moving to normoxic water. If, however, our assumption that blue crabs prefer normoxia ( $>4 \mathrm{mg} \mathrm{l}^{-1}$ ) is incorrect, then an invalid assumption may help to understand our nonsignificant results. Crabs that are frequently exposed to hypoxic water during upwelling events may become acclimated to low DO concentrations by increasing the oxygen affinity of hemocyanins in the blood (Mangum 1994). Hypoxic upwelling events are frequent in this part of the NRE (Luettich et al. 2000, this study), and exposure to mild and severe hypoxia may be common for some crabs (as much as $64.5 \%$ of crab relocations were mildly hypoxic and $17.3 \%$ severely hypoxic). Consequently, crabs in our study site may be conditioned to tolerate mild hypoxia ( 2 to $4 \mathrm{mg} \mathrm{l}^{-1}$ ) rather than search for normoxia (>4 $\mathrm{mg} \mathrm{l}^{-1}$ ) during hypoxic upwelling events. Our telemetry results support this conclusion. For example, when DO dropped from normoxia to mild hypoxia, crabs remained in mild hypoxia $71 \%$ of the time. Moreover, when DO dropped from normoxia to severe hypoxia, crabs moved to normoxia or mild hypoxia (i.e. DO > $2 \mathrm{mg} \mathrm{l}^{-1}$ ) $86 \%$ of the time. If blue crabs acclimate to mild hypoxia, then perhaps our crabs did not fail to avoid hypoxia, rather, they may have preferred DO concentrations greater than $2 \mathrm{mg}$ $\mathrm{l}^{-1}$ (not greater than $4 \mathrm{mg}^{-1}$ ). Therefore, DO less than $2 \mathrm{mg}^{-1}$ may constitute hypoxia for blue crabs.

Hypoxic upwelling events may alter the trophic dynamics between mobile benthic predators and their infaunal prey if predators reinvade recently hypoxic offshore habitats to take advantage of infaunal prey that have reduced their burial depth (Pihl et al. 1991, Breitburg et al. 1994). Although telemetered blue crabs did not reinvade deeper water habitats during relaxation events, these crabs were exposed to hypoxia 
prior to the increase in DO. Blue crabs become quiescent during prolonged exposure to hypoxia and may take several hours after exposure to resume normal movement activity (Lowery \& Tate 1986, DeFur et al. 1990, Das \& Stickle 1994). Therefore, crabs may have taken so long to resume normal movement activity after exposure to hypoxia that our analysis of movement responses to increasing DO from mild or severe hypoxia may not have detected movement to deeper habitats. Alternatively, blue crabs may not have exploited shallow-buried infauna after relaxation events because the nearshore habitats in our study site were hypoxic for only a few hours. Nearshore habitats in Chesapeake Bay were hypoxic for several days before demersal fish could exploit infaunal prey (Diaz et al. 1992, Pihl et al. 1992). Thus, during our study, hypoxic upwelling events may not have lasted long enough for infauna to vertically migrate to shallow depths that would make them more susceptible to blue crab predation.

\section{Predicted population responses to episodic hypoxia}

Based on the proportion of times that crabs remained in severely hypoxic water when DO dropped from normoxia to severe hypoxia, we would predict that as much as $14 \%$ of the local blue crab population would occur within severely hypoxic water during upwelling events. This is inconsistent with results from a nearby quasi-concurrent trawl survey which did not catch blue crabs in areas with DO concentrations less than $2.3 \mathrm{mg} \mathrm{l}^{-1}$ (Eby \& Crowder 2002). The inconsistency between our biotelemetry results and Eby \& Crowder's (2002) trawl survey results may be due to differences between the spatial and temporal scales of trawl sampling and those of hypoxic upwelling events. The biweekly, system-wide (entire NRE) trawl survey by Eby \& Crowder (2002) may not have sampled nearshore habitats frequently enough to capture hypoxic upwelling events that typically last only a few hours in this region of the NRE (Luettich et al. 2000, this study). When hypoxic upwelling events in the NRE were targeted by a trawl survey using a net similar to that of Eby \& Crowder (2002), blue crabs were collected from nearly anoxic $\left(0.25 \mathrm{mg} \mathrm{l}^{-1}\right)$ nearshore habitats during an upwelling event (Bell 2002). The number of crabs that were collected in hypoxic water comprised $10 \%$ of the local blue crab population, which is close to the $14 \%$ predicted by our telemetry results. The agreement between our biotelemetry results and Bell's (2002) trawling study results suggests that the inconsistency between our study and that of Eby \& Crowder (2002) may be due to their trawl survey not sampling at the temporal scales of hypoxic upwelling events.
Understanding the movement responses of free ranging blue crabs to episodic hypoxic disturbance will help predict how the hydrodynamics of these events impact blue crab behavior, and subsequent distribution and abundance patterns. We know little about the mechanisms blue crabs and other mobile estuarine species use to detect and avoid hypoxia. To fully understand the patterns of blue crab movement behavior observed in this study, and to determine the consequences of episodic hypoxic disturbance on blue crab distribution and abundance patterns, future studies are needed to identify the mechanisms blue crabs use to sense hypoxia and orient to spatial and temporal oxygen gradients. Our biotelemetry study demonstrates that the movement response of free-ranging individuals to disturbance events can be scaled up to predict changes in the abundance and distribution patterns of local populations.

Acknowledgements. We thank the numerous graduate student volunteers and technicians for their hard work during the field season, including: R. Aguilar, C. Bergeron, J. Chaves, G. Dickel XII, A. Drew, L. Etherington, M. Fitchett, E. Johnson, D. Kirkiewiz, H. Major, C. Marquette, H. Preston, N. Reyns, and M. Weiner. We are grateful to W. Showers for the use of his datasondes. We also thank M. Fuentes, J. Hightower, and 4 anonymous reviewers for their valuable scientific and editorial comments that improved the content of this manuscript. Financial support for this project was provided by grants from the North Carolina Sea Grant Program to D.B.E. and T.G.W. (R/MRD-43), the National Science Foundation (OCE97-34472) to D.B.E. and the Sigma Xi Scientific Research Society to G.W.B.

\section{LITERATURE CITED}

Batterton CV, Cameron JN (1978) Characteristics of resting ventilation and response to hypoxia, hypercapnia, and emersion in the blue crab Callinectes sapidus (Rathbun). J Exp Zool 203:403-418

Bell GW (2002) Behavioral response of free-ranging blue crabs to episodic hypoxia. MSc thesis, North Carolina State University, Raleigh

Breitburg DL (1992) Episodic hypoxia in Chesapeake Bay: interacting effects of recruitment, behavior, and physical disturbance. Ecol Monogr 62:525-546

Breitburg DL, Steinberg ND, DuBeau S, Cooksey C, Houde ED (1994) Effects of low dissolved oxygen on predation on estuarine fish larvae. Mar Ecol Prog Ser 104:235-246

Buzzelli CP, Luettich RA Jr, Powers SP, Peterson CH, McNinch JE, Pinckney JL, Paerl HW (2002) Estimating the spatial extent of bottom-water hypoxia and habitat degradation in a shallow estuary. Mar Ecol Prog Ser 230:103-112

Clark ME, Wolcott TG, Wolcott DL, Hines AH (1999a) Foraging and agonistic activity co-occur in free-ranging blue crabs (Callinectes sapidus): observation of animals by ultrasonic telemetry. J Exp Mar Biol Ecol 233:143-160

Clark ME, Wolcott TG, Wolcott DL, Hines AH (1999b) Intraspecific interference among foraging blue crabs Callinectes sapidus: interactive effects of predator density and prey patch distribution. Mar Ecol Prog Ser 178:69-78 
Clark ME, Wolcott TG, Wolcott DL, Hines AH (2000) Foraging behavior of an estuarine predator, the blue crab Callinectes sapidus in a patchy environment. Ecography 23: $21-31$

Collazo JA, Epperly SP (1995) Accuracy tests for sonic telemetry studies in an estuarine environment. J Wildl Manag 59:181-188

Das T, Stickle WB (1993) Sensitivity of crabs Callinectes sapidus and $C$. similis and the gastropod Stramonita haemastoma to hypoxia and anoxia. Mar Ecol Prog Ser 98: 263-274

Das T, Stickle WB (1994) Detection and avoidance of hypoxic water by juvenile Callinectes sapidus and C. similis. Mar Biol 120:593-600

DeFur PL, Mangum CP, Reese JE (1990) Respiratory responses of the blue crab Callinectes sapidus to long-term hypoxia. Biol Bull 178:46-54

Diaz RJ, Rosenberg R (1995) Marine benthic hypoxia: a review of its ecological effects and the behavioural responses of benthic macrofauna. Oceanogr Mar Biol Annu Rev 33:245-303

Diaz RJ, Neubauer RJ, Schaffner LC, Pihl L, Baden SP (1992) Continuous monitoring of dissolved oxygen in an estuary experiencing periodic hypoxia and the effect of hypoxia on macrobenthos and fish. Sci Total Environment (Suppl) 1992:1055-1068

Eby L (2001) Response of a fish community to frequent and infrequent disturbances in an estuarine ecosystem. PhD thesis, Duke University, Durhan, NC

Eby LA, Crowder LB (2002) Hypoxia-based habitat compression in the Neuse River Estuary: context-dependent shifts in behavioral avoidance thresholds. Can J Fish Aquat Sci 59:952-965

Grasso FW, Consi TR, Mountain DC, Atema J (2000) Biomimetic robot lobster performs chemo-orientation in turbulence using a pair of spatially separated sensors: progress and challenges. Robotics and Autonomous Systems 30:115-131

Herrnkind WF (1983) Movement patterns and orientation. In: Vernberg FJ, Vernberg WB (eds) The biology of Crustacea, Vol 7. Academic Press, New York, p 41-105

Hines AH, Haddon AM, Wiechert LA (1990) Guild structure and foraging impact of blue crabs and epibenthic fish in a subestuary of Chesapeake Bay. Mar Ecol Prog Ser 67: 105-126

Judy MH, Dudley DL (1970) Movements of tagged blue crabs in North Carolina waters. Commer Fish Rev 32:29-35

Lenihan HS, Peterson CH (1998) How habitat degradation through fishery disturbance enhances impacts of hypoxia on oyster reefs. Ecol Appl 8:128-140

Lenihan HS, Peterson CH, Byers JE, Grabowski JH, Thayer GW, Colby DR (2001) Cascading of habitat degradation: oyster reefs invaded by refuge fishes escaping stress. Ecol Appl 11:764-782

Loesch H (1960) Sporadic mass shoreward migrations of demersal fish and crustaceans in Mobile Bay, Alabama. Ecology 41:292-298

Lowery TA, Tate LG (1986) Effect of hypoxia on hemolymph lactate and behavior of the blue crab Callinectes sapidus Rathbun in the laboratory and field. Comp Biochem Physiol A 85:689-692

Luettich RA Jr, McNinch JE, Paerl HW, Peterson CH, Wells

Editorial responsibility: Otto Kinne (Editor),

Oldendorf/Luhe, Germany
JT, Alperin M, Martens CS, Pinckney JL (2000) Neuse River Estuary modeling and monitoring project stage 1: Hydrography and circulation, water column nutrients and productivity, sedimentary processes and benthic-pelagic coupling, and benthic ecology. Report No. 325-B. Water Resources Research Institute, University of North Carolina

Mangum CP (1994) Subunit composition of hemocyanins of Callinectes sapidus: phenotypes from naturally hypoxic waters and isolated oligomers. Comp Biochem Physiol B Comp Biochem Mol Biol 108:537-541

Mangum CP (1997) Adaptation of the oxygen transport system to hypoxia in the blue crab, Callinectes sapidus. Am Zool 37:604-611

McClellan CM (2001) Mesoscale habitat use of juvenile southern flounder, Paralichthys lethostigma: responses to environmental variability. MSc thesis, Duke University

Nevitt GA, Pentcheff ND, Lohmann KJ, Zimmerfaust RK (1995) Evidence for hydrodynamic orientation by spiny lobsters in a patch reef environment. J Exp Biol 198: 2049-2054

Nye LA (1989) Variation in feeding behavior of blue crabs (Callinectes sapidus Rathbun) measured by ultrasonic biotelemetry. MSc thesis, North Carolina State University, Raleigh

Officer CB, Biggs RB, Taft JL, Cronin LE, Tyler MA, Boynton WR (1984) Chesapeake Bay anoxia: origin, development, and significance. Science 223:22-27

Pihl L, Baden SP, Diaz RJ (1991) Effects of periodic hypoxia on distribution of demersal fish and crustaceans. Mar Biol 108:349-360

Pihl L, Baden SP, Diaz RJ, Schaffner LC (1992) Hypoxiainduced structural changes in the diet of bottom-feeding fish and crustacea. Mar Biol 112:349-361

Sanford LP, Sellner KG, Breitburg DL (1990) Covariability of dissolved oxygen with physical processes in the summertime Chesapeake Bay. J Mar Res 48:567-590

Taylor EW (1982) Control and co-ordination of ventilation and circulationin crustaceans: responses to hypoxia and exercise. J Exp Biol 100:289-319

Weissburg MJ, Dusenbery DB (2002) Behavioral observations and computer simulations of blue crab movement to a chemical source in a controlled turbulent flow. J Exp Biol 205:3387-3398

Weissburg MJ, Zimmerfaust RK (1993) Life and death in moving fluids: hydrodynamic effects on chemosensorymediated predation. Ecology 74:1428-1443

Weissburg MJ, James CP, Smee DL, Webster DR (2003) Fluid mechanics produces conflicting constraints during olfactory navigation of blue crabs, Callinectes sapidus. J Exp Biol 206:171-180

Wolcott TG, Hines AH (1989) Ultrasonic biotelemetry of muscle activity from free-ranging marine animals: a new method for studying foraging by blue crabs (Callinectes sapidus). Biol Bull 176:50-56

Wolcott TG, Hines AH (1990) Ultrasonic telemetry of smallscale movements and microhabitat selection by molting blue crabs (Callinectes sapidus). Bull Mar Sci 46:83-94

Zhou T, Rebach S (1999) Chemosensory orientation of the rock crab. J Chem Ecol 25:315-329

Zar JH (1984) Biostatistical analysis. Prentice-Hall, Englewood Cliffs, NJ

Submitted: October 21, 2002; Accepted: June 6, 2003

Proofs received from author(s): August 26, 2003 